\title{
Kinetics of Ultrasonic Transesterification of Waste Cooking Oil
}

\author{
Georgene Elizabeth Grant and Veera Gnaneswar Gude \\ Civil and Environmental Engineering Department, Mississippi State University, Mississippi State, MS 39762; \\ gude@cee.msstate.edu (for correspondence)
}

Published online 00 Month 2013 in Wiley Online Library (wileyonlinelibrary.com). DOI 10.1002/ep.11863

\begin{abstract}
This study reports the kinetics of ultrasonic transesterification of waste cooking oil into fatty acid methyl esters (FAMES). Direct sonication of waste cooking oil under controlled external temperatures was performed. Transesterification kinetics under the influence of direct sonication was studied using eight different individual reaction orders with respect to waste cooking oil and methanol. The results show that reaction temperature has a very small effect on the transesterification reaction under direct sonication. The reaction rate constants for different temperatures (35, 45, 55, and $65^{\circ} \mathrm{C}$ ) are determined as: $10.642 \mathrm{~g}^{2} \mathrm{~mol}^{-2} \mathrm{~min}^{-1}$; 7.053; 7.9727; $10.971 \mathrm{~g} \mathrm{~mol}^{-1} \mathrm{~min}^{-1}$ respectively and the activation energy of the ultrasonic transesterification of waste cooking oil was 19,645 $\mathrm{J} \mathrm{mol}^{-1} \mathrm{~K}^{-1}$. (C) 2013 American Institute of Chemical Engineers Environ Prog, O0: 000-000, 2013

Keywords: biodiesel kinetics, ultrasonic transesterification, waste cooking oil, reaction kinetics, activation energy
\end{abstract}

\section{INTRODUCTION}

Use of waste cooking oils as feedstock for biodiesel production has several benefits. They are often available at low or free of cost. They do not release any environmental emissions in their production since they originate from already existing oil sources [1,2]. Recently, many studies have focused on the transesterification of waste cooking oils into biodiesel using both conventional and nonconventional methods. Conventional, supercritical, and noncatalytic conversion (without catalyst) of waste cooking oils into biodiesel was studied [3-8]. Since conventional methods (water or oil bath and hot plate or electric heating) require longer reaction times and supercritical process conditions require high process equipment safety (high capital cost), nonconventional methods such as ultrasonics and microwaves have been explored recently. Ultrasonic technology has attracted the researchers due to the safety and simplicity of the process reactors. Biodiesel synthesis assisted by ultrasonic irradiation was tested on many feedstock such as vegetable oils, soybean oil, sunflower oil, bleached tallow oils, palm fatty acid distillate [9-18]. In all these studies, the beneficial effects of ultrasound on the transesterification reaction were reported as: marked enhancement in reaction rates, high yields at low alcohol to oil molar ratios and reduction in reaction temperature required for high conversion of oils.

Kinetics of transesterification reaction (also known as alcoholysis) using conventional methods were reported for

(ㄷ) 2013 American Institute of Chemical Engineers many biodiesel feedstock including palm oil, rapeseed oil, soybean oil, vegetable oils, sunflower oil, jatropha curcas, waste cooking oil, noncatalytic transesterification of soybean oils, oleic acid, pongamia oil, and palm fatty acids [19-33]; however, the kinetics of ultrasonic transesterification was reported in only a few studies. Kinetics of ultrasonic assisted transesterification of soybean oil was reported by Colucci et al. and Parkar et al. [15,34]. Colucci et al. reported a pseudo second-order kinetic model for the hydrolysis of oils and reaction rate constants of three to five times higher than those for mechanical agitation [15]. Parker et al. compared the ultrasonic transesterification of soybean oil with conventional alkali catalyzed reaction with mechanical stirring. They studied inter-relation between mechanics of ultrasound/cavitation, and the intrinsic behavior (represented by specific rate constant) of the transesterification reaction. The study proposed a first order kinetic model [34]. Mahamuni and Adewuyi [35] reported that the methanolysis reaction for conversion of soybean oil to biodiesel in the presence of ultrasound at $35^{\circ} \mathrm{C}$ is second-order (first-order with respect to both oil and methanol). On the other hand, Georgogianni et al. [14] reported the first- and second-order reaction with respect to TAG (Triglycerides) for the base-catalyzed methanolysis of sunflower and cottonseed oils using both low frequency ultrasonication and mechanical agitation, although a better fit was obtained for the first-order reaction kinetics. Deshmane et al. [36] verified a kinetic model based on the first-order reaction followed by the second-order with respect to fatty acids for ultrasound-assisted acid-catalyzed esterification of palm fatty acid distillate. In another study, they also reported pseudo-first order reaction kinetics for calcium methoxide solid base catalyzed transesterification of soybean oil [37]. Empirical modeling of ultrasound assisted base-catalyzed sunflower oil methanolysis kinetics was studied by Avramovic et al. [38]. Effects of molar ratio, alkali catalyst concentration and temperature on transesterification of jatropha oil with methanol under ultrasonic irradiation and their kinetics were evaluated by first order reaction kinetics [39]. Kinetics of used soybean frying oil was reported to follow a first-order reaction kinetic model by Lee et al. [40].

Since feedstock costs account for a large percent of the direct biodiesel production costs, use of waste cooking oils or inedible and low cost oils (ex: camelina sativa) can reduce the biodiesel production costs [41-44]. Although, the kinetics of many virgin feedstock (oils) were reported by several researchers, kinetics of waste cooking oils using ultrasonic method, and base catalyzed reaction has not been reported thus far. Also, the reaction rates with respect to individual 
reactants such as oil and methanol were not reported in many studies. This is important because the kinetics of transesterification reaction depends on both the reactants and their individual interaction with ultrasonics especially at different reaction temperatures. In this research work, we have studied the kinetics of ultrasonic transesterification of waste cooking oil (used canola oil) under controlled temperatures. Reaction rate constants and reaction orders were estimated using conversion vs. reaction time data for oil and methanol using the equations derived from the proposed model considering eight different cases. Activation energy was obtained from reaction rate constants at different temperatures $(45,55$ and $65^{\circ} \mathrm{C}$ ) for the base catalyzed transesterification reaction. Mathematical model and results obtained from this research are discussed in the following sections along with a comparison of conventional transesterification kinetics.

\section{MATERIALS AND METHODS}

\section{Materials}

Perry Market Cafeteria located on Mississippi State University (MSU) campus provided the waste cooking oil. Methanol and the catalyst (sodium hydroxide, $\mathrm{NaOH}$ ) were purchased from Fisher Scientific. Methanol used in this study was of ACS certified grade.

\section{Ultrasonic Irradiation Unit}

Sonic dismembrator (Model 550 from Fisher Scientific) served as the main processing unit in this study. The sonicator has power output of $500 \mathrm{~W}$ at a fixed frequency of 20 $\mathrm{kHz}$ with the following dimensions: $12.7 \mathrm{~cm} \mathrm{~L} \times 3.8 \mathrm{~cm}$ diametertapered to $12.7 \mathrm{~mm}$ tip diameter $\left(1.22 \mathrm{~cm}^{2}\right.$, maximum intensity $-410 \mathrm{~W} \mathrm{~cm}^{-2}$ ). The horn is made of titanium alloy with ten levels of amplitude to vary the effect of ultrasonic application. Continuous mode of ultrasonic application was used in the experiments with an amplitude level of 3 .

\section{Biodiesel Analysis by Gas Chromatography}

The analysis was carried out on a Varian Gas Chromatography (GC) with cool on column injection and FID detection as required by ASTM 6584 method for B100. The operating scheme of the biodiesel analysis using the gas chromatography is as follows: a sample size of $1 \mu \mathrm{l}$ with initial temperature of $50^{\circ} \mathrm{C}$ (hold $1 \mathrm{~min}$ ) followed by rate $1\left(15^{\circ} \mathrm{C} / \mathrm{min}\right.$ to $\left.180^{\circ} \mathrm{C}\right)$; rate $2\left(7^{\circ} \mathrm{C} / \mathrm{min}\right.$ to $\left.230^{\circ} \mathrm{C}\right)$ and rate $3\left(30^{\circ} \mathrm{C} / \mathrm{min}\right.$ $380^{\circ} \mathrm{C}$ ) with flame ionization detector at $380^{\circ} \mathrm{C}$. Helium was used as a carrier gas.

\section{KINETIC MODEL FOR CANOLA OIL METHANOLYSIS}

\section{Transesterification Reaction Scheme}

The reaction considered for the present study is a typical transesterification reaction of oil and alcohol in the presence of a strong Lewis base catalyst (ex: $\mathrm{NaOH}$ ) producing methyl esters and glycerol. The reaction scheme is shown in Figure 1. Ultrasonics are utilized as a nonconventional energy source to promote mixing in the transesterification reaction.

Ultrasonic irradiation differs from traditional energy sources (heat, light, or ionizing radiation) in duration, pressure,

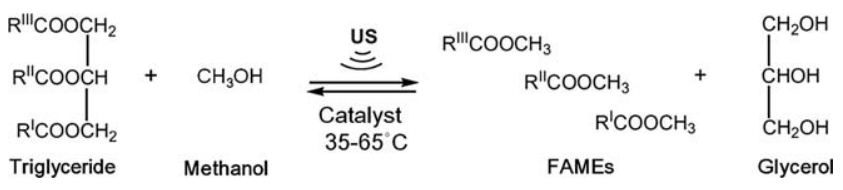

Figure 1. Transesterification reaction scheme using ultrasonics under controlled temperatures. and energy per molecule. The immense local temperatures and pressures and the extraordinary heating and cooling rates generated by cavitation bubble collapse provide an unusual mechanism for generating high-energy chemistry. Similar to photochemistry, very large amounts of energy are introduced in a short period of time (in microseconds) to create hot spots that have equivalent temperatures of roughly $5000 \mathrm{~K}$, but it is thermal, not electronic excitation. As in flash pyrolysis, high thermal temperatures can be reached, but the duration is very much shorter (by $>10^{4}$ ) and the temperatures are even higher (by five- to ten-fold) in sonication $[45,46]$.

\section{Chemistry of the Reaction}

The overall triglyceride transesterification reaction is reversible and excess amount of alcohol is used to shift the equilibrium towards the formation of esters. Generalized transesterification reaction is given by Eq. (1), where A is the triglyceride, $\mathrm{B}$ is the methanol, $\mathrm{C}$ is the FAME and $\mathrm{D}$ is glycerol.

\section{Initial Assumptions}

For this kinetic study, the following assumptions were made:

1. As the waste cooking oil is refined (after the pretreatment), the proportion of free fatty acid was negligible, and the free fatty acid neutralization was insignificant.

2. It was also considered that the saponification reaction was insignificant because of the low acid value of the oil $(3.0 \mathrm{mg}$ of $\mathrm{KOH} / \mathrm{g}$ ) and reactions were carried out at optimal reaction temperatures using homogeneous base catalyst.

\section{Mathematical Analysis}

Since the effect of ultrasound on the triglycerides and methanol can be different, we have used the reaction kinetic equations that consider individual reaction rate orders with respect to the reactants in the reactant mixture (oil and methanol) [47]. The development of the reaction kinetics is as follows:

$$
\mathrm{A}+3 \mathrm{~B} \leftrightarrow \mathrm{C}+\mathrm{D}
$$

The general rate equation for the equation shown in Figure 1 is:

$$
-\frac{d C_{A}}{d t}=k C^{\alpha}{ }_{A} C^{\beta}{ }_{B}
$$

where $C_{A} / t$ is the consumption of reactant A per unit time, $\mathrm{k}$ is a rate constant, $C_{A}$ is the concentration of $\mathrm{A}$ after time t, $C_{B}$ is the concentration of $\mathrm{B}$ after time $\mathrm{t}, \alpha$ is the order of reactant $\mathrm{A}$, and $\beta$ is the order of reactant $\mathrm{B}$. In addition:

$$
\begin{aligned}
& C_{A}=C_{A 0}(1-X) \\
& C_{B}=C_{A 0}\left(\theta_{B}-3 X\right) \\
& \theta_{B}=\frac{C_{B 0}}{C_{A 0}}
\end{aligned}
$$

where $C_{A O}$ and $C_{B O}$ are the initial concentrations of $\mathrm{A}$ and $\mathrm{B}$, $\mathrm{X}$ is the conversion of triglycerides, and $\theta_{B}$ is the ratio of $C_{B O}$ to $C_{A O}$. Eq. (2) can be rewritten as:

$\frac{d X}{d t}=k C_{A 0}{ }^{\alpha+\beta-1}(1-X)^{a}\left(\theta_{B}-3 X\right)^{\beta}$

In the present work, eight different cases were considered in order to obtain the reaction order. These cases were 
$(\alpha=0, \beta=0),(\alpha=1, \beta=0),(\alpha=0, \beta=1),(\alpha=1, \beta=1)$, $(\alpha=2, \beta=0),(\alpha=0, \beta=2),(\alpha=2, \beta=1),(\alpha=1, \beta=2)$. For each case, definite integrals of Eq. (6) were calculated from a conversion of $X=0$ to a conversion of $X=X$ in the time span of $t=0$ to $t=t$. The calculated equation for each case was then transferred into a linear equation passing through origin $(y=m x)$. The transferred equations for each of the case are as follows:

(a) Case 1: $(\alpha=0, \beta=0)$

$C_{A 0} X=k t$

(b) Case 2: $(\alpha=1, \beta=0)$

$\ln \left[\frac{1}{1-X}\right]=k t$

(c) Case 3: $(\alpha=0, \beta=1)$

$-\frac{1}{3}\left[\ln \frac{\theta_{B}-3 X}{\theta_{B}}\right]=k t$

(d) Case 4: $(\alpha=1, \beta=1)$

$\frac{1}{\left(\theta_{B}-3\right)} \ln \left[\frac{\left(\theta_{B}-3 X\right)}{(1-X) \theta_{B}}\right]=k C_{A 0} t$

(e) Case 5: $(\alpha=2, \beta=0)$

$\frac{X}{(1-X)}=k C_{A 0} t$

(f) Case 6: $(\alpha=0, \beta=2)$

$\frac{X}{\left(\theta_{B}-3 X\right) \theta_{B}}=k C_{A 0} t$

(g) Case 7: $(\alpha=2, \beta=1)$

$\frac{1}{\left(\theta_{B}-3\right)}\left\{\frac{X}{(1-X)}-\frac{3}{\left(\theta_{B}-3\right)} \ln \left[\frac{\left(\theta_{B}-3 X\right)}{(1-X) \theta_{B}}\right]\right\}=k C_{A 0}^{2} t$

(h) Case 8: $(\alpha=1, \beta=2)$

$\frac{1}{\left(3-\theta_{B}\right)}\left\{\frac{3 X}{\left(\theta_{B}-3 X\right) \theta_{B}}-\frac{1}{\left(3-\theta_{B}\right)} \ln \left[\frac{(1-X) \theta_{B}}{\left(\theta_{B}-3 X\right)}\right]\right\}=k C_{A 0}^{2} t$

For Eqs. (7-14), if it is assumed that the left-side component is an ordinate ( $y$ variable) and $\mathrm{t}$ (for Eqs. (7-9)), $\mathrm{C}_{\mathrm{A} 0} \mathrm{t}$ (for Eqs. (10-12)) and $\mathrm{C}_{\mathrm{A} 0}{ }^{2} \mathrm{t}$ (for Eqs. (13) and (14)) are abscissas $(x$ variables), respectively, the equations are in the form of $y=m x$ (a straight line passing through origin). For all eight cases, the $y$ variable was plotted against the corresponding $x$ variable and the coefficient of determination was estimated. In all cases for Eqs. (7-14), the slope of the straight line is the rate constant, $k$, for the reaction. The highest correlation coefficient, $R^{2}$, for each case was observed and the case that gave the highest correlation coefficient was used to determine the reaction order and reaction rate constants.

\section{Determination of Activation Energy}

The Arrhenius equation gives a relationship between the specific reaction rate constant $(k)$, absolute temperature $(T)$ and the energy of activation $\left(E_{a}\right)$ as:

$k=A * \exp \left[-\frac{E_{a}}{R T}\right]$

where $A$ is the frequency factor and $R$ is universal gas con$\operatorname{stant}\left(\mathrm{J} \mathrm{mol}^{-1} \mathrm{~K}^{-1}\right)$. This equation can be rewritten as:

$\ln (k)=-\frac{E_{a}}{R T}+\ln (A)$

A plot of $\ln (k)$ vs $1 / T$ (the Arrhenius plot) gives slope equal to $\left(-E_{d} / R\right)$ from which activation energy can be determined.

\section{RESULTS AND DISCUSSION}

\section{Process Optimization}

Thermal effects of direct sonication on waste cooking oil conversion into biodiesel without any external heating were investigated in a previous study [1]. The study investigated the effect of different catalyst concentrations (0.5-2\% wt, $\mathrm{NaOH})$, methanol to oil molar ratios of $1: 4.5$ to $1: 13.5$ and reaction times between 0.5 and $2.5 \mathrm{~min}$. Sodium hydroxide was chosen due to its high FAME yields in short reaction time. The study demonstrated that the transesterification reaction can be completed in a very short reaction time as much as $120 \mathrm{~s}$ ( $2 \mathrm{~min}$ ) even without any temperature control settings. Application of amplitudes has shown to have a significant effect on the reaction completion although not very large. A catalyst amount of $0.5 \%$ (wt/wt) and methanol to oil ratio of 9:1 was found to be adequate to complete the transesterification reaction in $2 \mathrm{~min}$ and further reaction time did not improve the biodiesel conversion significantly. The biodiesel analysis (for canola waste cooking oil) showed the characteristic peaks similar to the biodiesel obtained from other high value virgin feedstock as shown in Figure 2. We have used the same optimum process conditions to study the kinetics of the ultrasonic transesterification reaction under controlled temperatures. The reaction temperatures were varied between $35^{\circ} \mathrm{C}$ and $65^{\circ} \mathrm{C}$ at $10^{\circ}$ intervals. The reaction was continued for $15 \mathrm{~min}$ to determine the maximum FAME conversion rates with a sampling interval of 2 min. The product (a mixture of fatty acid methyl esters and glycerol) was separated and was then transferred to a freezer before being sent for Gas Chromatography (GC) analysis.

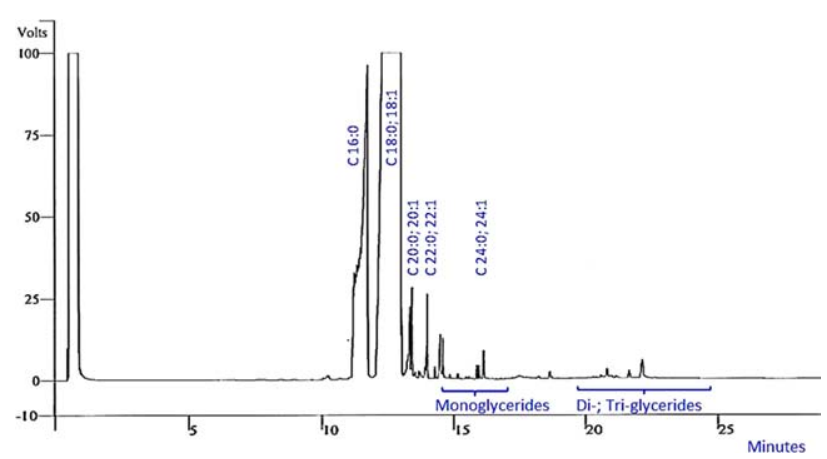

Figure 2. GC-Chromatogram of biodiesel obtained from waste cooking oil. [Color figure can be viewed in the online issue, which is available at wileyonlinelibrary.com.] 


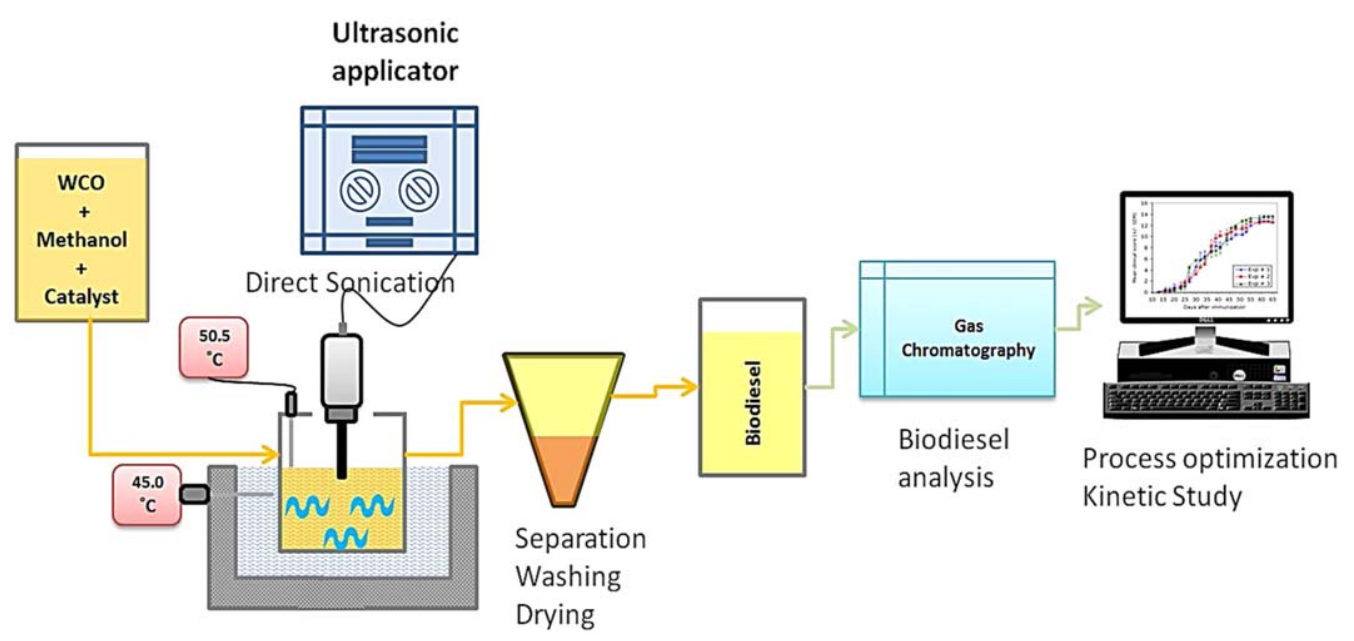

Figure 3. Experimental set-up for the ultrasonic transesterification of waste cooking oil. [Color figure can be viewed in the online issue, which is available at wileyonlinelibrary.com.]

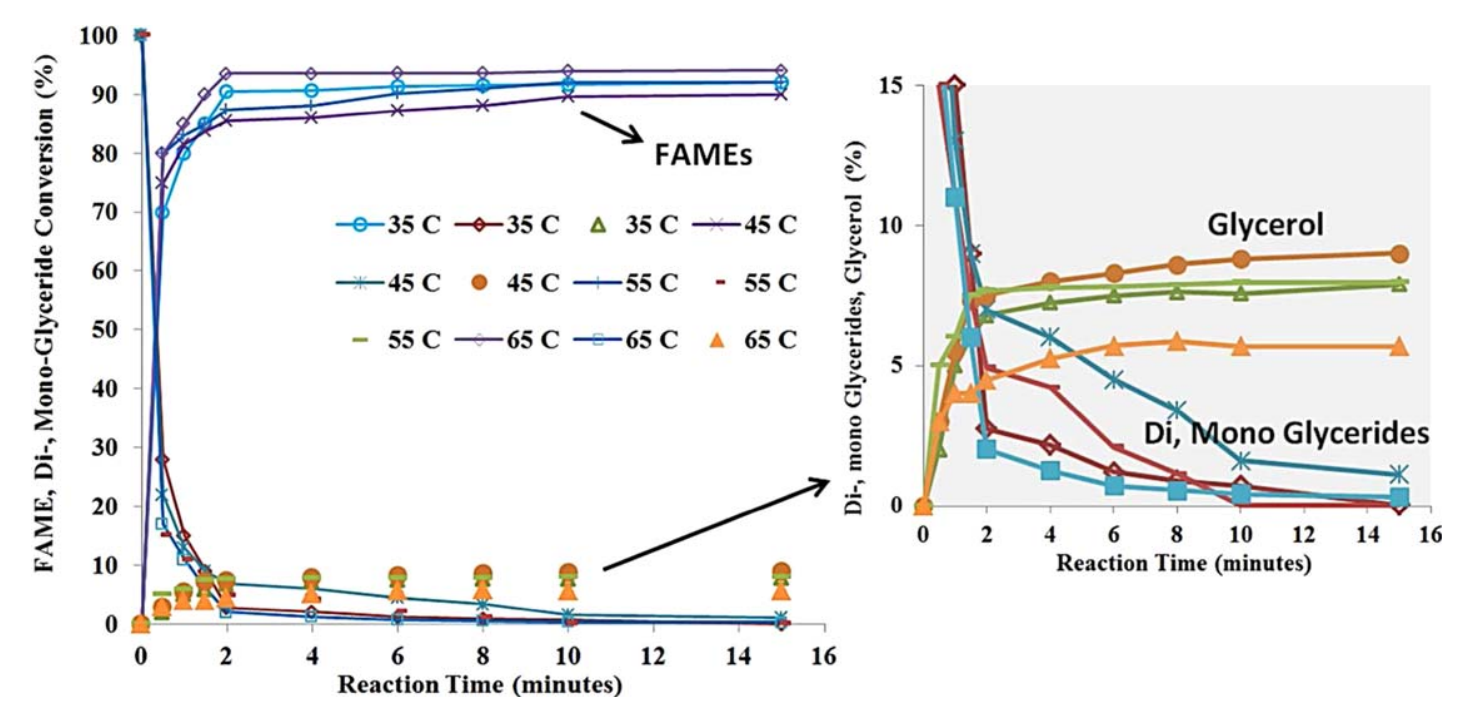

Figure 4. Profiles of triglycerides, fatty acid methyl esters, di-, mono-glycerides, and glycerol. [Color figure can be viewed in the online issue, which is available at wileyonlinelibrary.com.]

Results obtained from the GC provided the FAME conversion vs. reaction time data for further analysis.

\section{Temperature Profiles and FAMEs Conversion}

Several experiments were carried out to study the effect of reaction temperature on the conversion of waste cooking oil into biodiesel under ultrasonic irradiation. The experimental set-up is shown in Figure 3 . The reaction temperatures were varied between $35^{\circ} \mathrm{C}$ and $65^{\circ} \mathrm{C}$ at 10 degree intervals. The biodiesel conversion profiles are shown in Figure 4. The plot also shows the profiles for glycerol formation and remaining tri-, di-, and mono-glycerides for reaction times between 0 and $15 \mathrm{~min}$. As observed in many other studies [15,19,51], the FAME yield rates did not improve significantly after $10 \mathrm{~min}$ of reaction time suggesting shorter reaction times to be suitable for this reaction. Biodiesel conversion profiles and kinetics under ultrasonic mixing were described to follow two important regimes as the mass transfer limited regime and kinetics controlled regime in previous studies [37]. The profile (shape) showing these two types of regimes followed a sigmoidal curve during product formation (i.e., FAME conversion) in a few studies. In this study, we have observed a FAME conversion profile similar to that observed by Darnoko et al. [19] under the temperature effect. We have divided the data into two sets to represent two different segments of conversion profiles as shown in Figure 4. The rapid peak conversion of the triglycerides in the first 2 min of the reaction time followed by a different pattern (slow conversion) between 2 and 15 minute reaction time can be seen in Figure 4. In ultrasonic transesterification, higher temperatures did not reduce the time to reach maximum FAME conversion, similar to the observation made in other studies [19,37]. In these studies, it was demonstrated that, while the overall conversion of the process did not change with temperature, the rate of the transesterification process was increased with temperature. The time needed for the mass transfer to occur was shortened as temperature was increased, leading to a higher rate of transesterification [48].

\section{Reaction Rates and Constants}

We have applied the Eqs. (7-14) to study the best fit of the reaction kinetics using eight different cases considering different reaction orders with respect to the individual 
Table 1. The values of " $R$ " for all eight cases of each data set in ultrasonic transesterification.

\begin{tabular}{|c|c|c|c|c|c|c|c|c|}
\hline \multicolumn{5}{|c|}{ Coefficient of correlation, $R^{2}$ for all eight cases for Data set I } & \multicolumn{4}{|c|}{$R^{2}$ for all eight cases for Data set II } \\
\hline Temperature $\left({ }^{\circ} \mathrm{C}\right)$ & 35 & 45 & 55 & 65 & 35 & 45 & 55 & 65 \\
\hline Case 1 & 0.6845 & 0.5492 & 0.4968 & 0.5592 & 0.9344 & 0.91 & 0.818 & 0.8809 \\
\hline Case 2 & 0.9261 & 0.7012 & 0.6071 & 0.7824 & 0.9306 & 0.9156 & 0.8381 & 0.8803 \\
\hline Case 3 & 0.6963 & 0.5554 & 0.4968 & 0.5548 & 0.9346 & 0.9087 & 0.815 & 0.881 \\
\hline Case 4 & 0.8535 & 0.6414 & 0.5617 & 0.6996 & 0.9309 & 0.9149 & 0.835 & 0.8804 \\
\hline Case 5 & 0.9907 & 0.8791 & 0.7717 & 0.9737 & 0.9254 & 0.9179 & 0.8541 & 0.8798 \\
\hline Case 6 & 0.3427 & 0.3915 & 0.4092 & 0.3922 & 0.9348 & 0.9073 & 0.8119 & 0.881 \\
\hline Case 7 & 0.9979 & 0.849 & 0.7354 & 0.9527 & 0.9258 & 0.9178 & 0.8522 & 0.8798 \\
\hline Case 8 & 0.7105 & 0.5532 & 0.5086 & 0.6035 & 0.9308 & 0.9152 & 0.8364 & 0.8804 \\
\hline
\end{tabular}

Table 2. Reaction order for each of the reactants, overall order and rate constants.

\begin{tabular}{lcccccc}
\hline Temperature & $\begin{array}{c}\text { Reaction order } \\
\text { w.r.t. Oil }\end{array}$ & $\begin{array}{c}\text { Reaction order } \\
\text { w.r.t. MeOH }\end{array}$ & $\begin{array}{c}\text { Overall } \\
\text { order }\end{array}$ & $\begin{array}{c}\text { Rate } \\
\text { const. I }\end{array}$ & $\begin{array}{c}\text { Rate } \\
\text { const. II }\end{array}$ & Unit \\
\hline $35^{\circ} \mathrm{C}$ & 2 & 1 & 3 & 10.642 & 0.8007 & $\mathrm{~g}^{2} \mathrm{~mol}^{-2} \mathrm{~min}^{-1}$ \\
$45^{\circ} \mathrm{C}$ & 2 & 0 & 2 & 7.053 & 0.4693 & $\mathrm{~g} \mathrm{~mol} \mathrm{~min}^{-1}$ \\
$55^{\circ} \mathrm{C}$ & 2 & 0 & 2 & 7.9727 & 0.7186 & $\mathrm{~g} \mathrm{~mol} \mathrm{~min}^{-1}$ \\
$65^{\circ} \mathrm{C}$ & 2 & 0 & 2 & 10.971 & 0.2008 & $\mathrm{~g} \mathrm{~mol} \mathrm{~min}^{-1}$ \\
\hline
\end{tabular}

reactants. Table 1 shows the coefficients of correlation $\left(R^{2}\right.$ values) for different cases at four reaction temperatures. Reaction order for each of the reactants, overall order, and rate constants are shown in Table 2. As can be seen, the reaction rate constant at low reaction temperature $\left(35^{\circ} \mathrm{C}\right)$ was higher compared with the other temperatures. This is because the ultrasonic waves function well at low temperatures although the viscosity of the reaction mixture may have a significant effect on the ultrasonic effect. At lower reaction temperatures, the physical effects of cavitation bubble dynamics (viz. micro-convection and shock waves) are more pronounced, which are the primary cause leading to effects of unexplained behavior of transesterification reaction [34]. About same reaction rate constants were observed at a reaction temperature of $65^{\circ} \mathrm{C}$ which can be attributed to the miscibility of heterogeneous mixture of oil and alcohol. Figure 5 shows the plots for reaction rates at different temperatures. It was interesting to note that the reaction rates with respect to oil and methanol were different at low temperatures $\left(35^{\circ} \mathrm{C}\right)$ compared to higher temperatures. At $35^{\circ} \mathrm{C}$, second order w.r.t the triglycerides and first-order w.r.t. methanol were fitted better, and between 45 and $65^{\circ} \mathrm{C}$, second order w.r.t the triglycerides and zero-order w.r.t. methanol were found to be the best estimates. Since the interdependencies of the reaction rates are well taken into consideration in the proposed model, the results represent an accurate overall reaction rate order (for all the reactants based on individual reaction rates). The reaction rate constants for different temperatures $\left(35,45,55\right.$, and $\left.65^{\circ} \mathrm{C}\right)$ are determined as: $10.642 \mathrm{~g}^{2}$ $\mathrm{mol}^{-2} \mathrm{~min}^{-1}$ (reaction order 2 w.r.t oil and 1 w.r.t. methanol); 7.053 (2, 0); 7.9727 (2, 0); and10.971 (2, 0) $\mathrm{g} \mathrm{mol}^{-1}$ $\min ^{-1}$ respectively. This shows that the overall reaction order of the ultrasonic transesterification follows a second order reaction as observed in conventional transesterification processes. In a few studies, a second-order mechanism or a pseudo second-order mechanism was shown to be more suitable for predicting FAME conversion at any reaction time. Using a second-order mechanism, the initial concentrations of all reactants are needed; generally, these concentrations are known to depend on the given conditions. In contrast, using a pseudo second-order mechanism, an initial concentration of triglycerides (TG) and initial highest concentrations of di-glycerides (DG) and mono-glycerides (MG) are needed.
An initial concentration of TG is usually not a problem, but the highest concentrations of DG and MG must be determined. The reaction must be allowed to proceed for a minute to know these concentrations. Consequently, a pseudo second-order mechanism cannot predict a conversion yield for all reaction times unlike a second-order mechanism [32].

\section{Comparison with Conventional and Microwave Transesterification Kinetics}

Colucci et al. reported a pseudo second-order kinetic model for the ultrasonic hydrolysis of DG and TG and reaction rate constants were three to five times higher than those for mechanical agitation [15]. Parker et al. compared the ultrasonic transesterification of soybean oil with conventional alkali catalyzed reaction with mechanical stirring and reported similar effects [34]. In our previous study, we studied the transesterification kinetics of Camelina Sativa oil under conventional and microwave heating conditions using heterogeneous metal oxide catalysts [49]. In that study, we observed that the transesterification reaction followed a second order with respect to triglycerides and first order with respect to methanol for both conventional and microwave methods with heterogeneous catalyst $\mathrm{BaO}$ except that the reaction rate constant is two orders of magnitude (98.7 times) higher for microwave-assisted heating method. The reaction rate constants were 0.0526 and $5.195 \mathrm{~g}^{2} \mathrm{~mol}^{-2} \mathrm{~min}^{-1}$ for conventional and microwave methods respectively. This is reflected by the short reaction times required for microwave heating and efficient heating of the reaction compounds. In this study, we noticed that the reaction rate constants determined in this study are higher than those observed in our previous study since we used base catalyzed transesterification reaction conditions. Also, the reaction rate enhancements can be attributed to the increase in interfacial area and activity of the microscopic and macroscopic bubbles formed when ultrasonic waves of $20 \mathrm{kHz}$ were applied to a two-phase reaction system [15]. The major physical effect of sonication of reaction mixture is very fine emulsification that generates enormous interfacial area for reaction that overwhelms the effect of specific rate constant, which in turn is a function of activation energy and reaction temperature. 


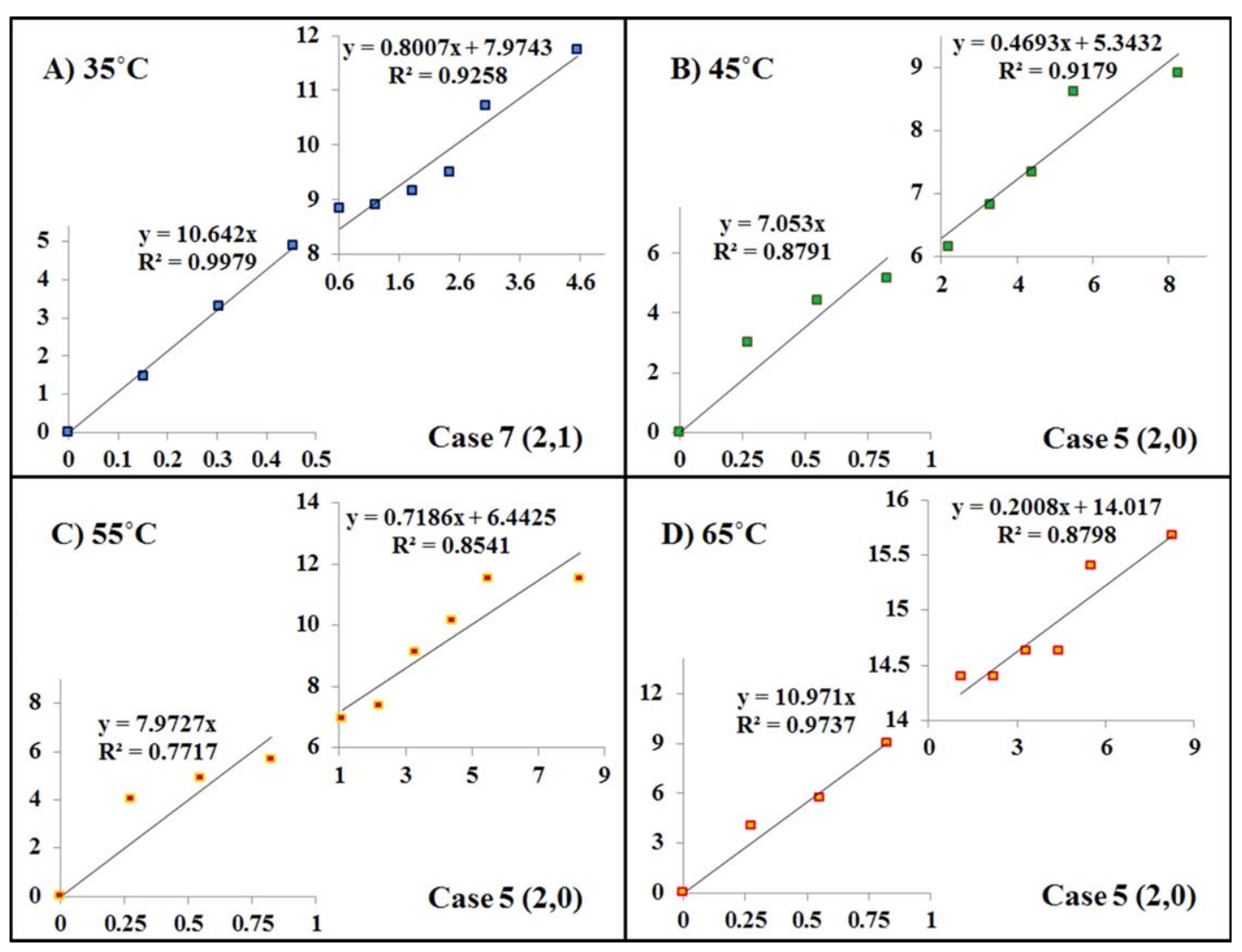

Figure 5. Kinetics of the ultrasonic transesterification of waste cooking oil at different temperatures. [Color figure can be viewed in the online issue, which is available at wileyonlinelibrary.com.]

\section{Activation Energy}

The activation energy was calculated using $\ln \mathrm{k}$ vs. $1 / \mathrm{T}$ (Eq. (16)) plot as shown in Figure 6. The activation energy observed is in the lower range of reported values in the literature. Deshmane reported an activation energy value of $64,000 \mathrm{~J} \mathrm{~mol}^{-1} \mathrm{~K}^{-1}$ [37] and Colucci reported in the similar range [15]. Vyas et al. reported the activation energy of ultrasonic transesterification of jatropha curcas oils as 16,691 J $\mathrm{mol}^{-1} \mathrm{~K}^{-1}$ [39]. These studies reported kinetics on pure vegetable or seed oils. Lee et al. reported the activated energy for used soybean frying oil of $29,000 \mathrm{~J} \mathrm{~mol}^{-1} \mathrm{~K}^{-1}[40]$. Krishnan and Dass reported very low activation energy values of 5,400-10,600 J mol${ }^{-1} \mathrm{~K}^{-1}$ for transesterification of waste cooking oil using conventional heating method (heating mantle) between 50 and $65^{\circ} \mathrm{C}$ [50]. In this study, we found the activation energy for the first data set as $19,645 \mathrm{~J}$ $\mathrm{mol}^{-1} \mathrm{~K}^{-1}$. It can be concluded that the activation energy depends on the reaction mixture (quality of oil, alcohol-catalyst) and the reaction conditions. Also, lower activation energies are desired as this is the minimum energy required to initiate a chemical reaction (or the energy that must be overcome in order for a reaction to occur). These results show that ultrasonic transesterification can easily initiate and complete the transesterification reaction within short periods of reaction time.

\section{Energy Requirements and Other Considerations}

Biodiesel, on average, contains an energy value of 33.335.6 MJ per liter [52]. In this study, $100 \mathrm{~mL}$ of waste cooking oil was converted to biodiesel using $150 \mathrm{~W}$ (at 30\% power) of ultrasonic energy for $10 \mathrm{~min}$. The conversion rate of oil to biodiesel was 92\%. The energy investment to convert the waste cooking oil into biodiesel was only $90 \mathrm{~kJ}$ which is
$2.8 \%$ of the energy available through biodiesel. In this study, the ultrasonic conversion of waste cooking oil process can be considered to occur in a continuously stirred tank reactor (CSTR), although no physical mixing was performed apart from the intense mixing that was caused by the acoustic wavelengths. The mixing caused by the ultrasound is more effective than the physical mixing that can be provided by conventional stirrers and agitators. This is due to the molecular level shear forces created by the acoustic waves and the air bubbles and their collapse that provide for enhanced heat and mass transfer area between the reactants in the reaction mixture. In large scale applications, multiple ultrasonic transducers will be required to provide uniform mixing effect by the ultrasound since the effect of ultrasound decreases with

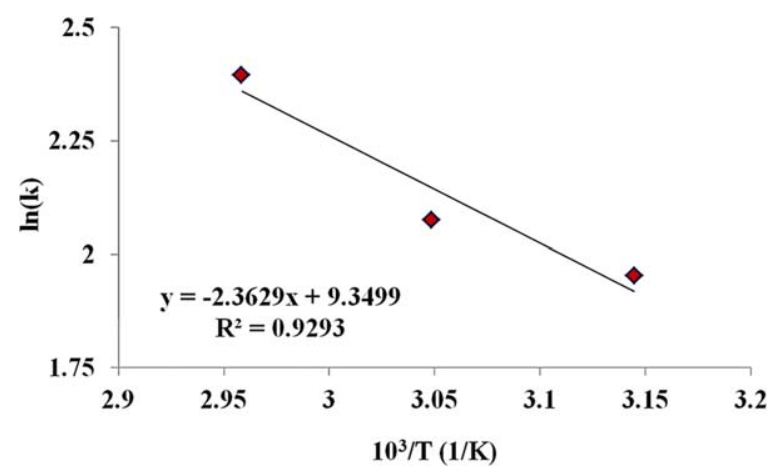

Figure 6. Activation energy of the ultrasonic transesterification of waste cooking oil. [Color figure can be viewed in the online issue, which is available at wileyonlinelibrary.com.] 
the distance from the probe. Another alternative is to consider a plug flow reactor for large scale applications. In plugtype or contact-type reactor design, ultrasonication can be employed in a small sample volume to complete the desired reaction in a short duration of reaction time. Process optimization and automation and control can be more challenging than other conventional systems in this case. Control of ultrasonic reactions is also subject to similar limitations as any thermal process; however, their intensity and energy supply can be controlled easily to achieve desired reactions [53]. Cavitational zone is another important factor which needs to be considered when designing the ultrasonic reactors. Acoustic streaming occurs generally away from the transducer surface towards the free surface and undergoes reflections at the reactor wall or the liquid surface generating a mixed recirculation. Although, basic design of ultrasonic horn is generally recommended for laboratory scale characterization studies, with some improvements such as longitudinally vibrating horn, large scale continuous processing can be feasible [54].

\section{CONCLUSIONS}

This study investigated the kinetics of ultrasonic assisted transesterification of canola waste cooking oil. Identifying the reaction rates with respect to individual reactants and overall reaction rate will be beneficial for the design and construction of the biodiesel reactors. This information is also useful in estimating the reaction times and reactor costs. In this study, the transesterification reaction was shown to follow second and first order reaction kinetics with respect to oil and methanol respectively at $35^{\circ} \mathrm{C}$ and at higher reaction temperatures $\left(45,55\right.$, and $\left.65^{\circ} \mathrm{C}\right)$, second and zero order reaction kinetics with respect to oil and methanol respectively. This study can be very instrumental in selecting the appropriate amounts of reaction compounds, catalyst concentrations and the ultrasonic effect. The reaction kinetics allow for better understating of the reactor design and efficient utilization of energy with higher FAMEs yields.

\section{NOMENCLATURE}

\section{List of Symbols}

$\alpha \quad$ reaction order w.r.t. triglyceride

$\beta \quad$ reaction order w.r.t. methanol

$\mathrm{C}_{\mathrm{A} 0}$ initial concentration of triglyceride, $(\mathrm{g} / \mathrm{L})$

$\mathrm{C}_{\mathrm{B} 0}$ initial concentration of methanol, $(\mathrm{g} / \mathrm{L})$

$\mathrm{C}_{\mathrm{A}} \quad$ concentration of triglyceride after time $\mathrm{t},(\mathrm{g} / \mathrm{L})$

$\mathrm{C}_{\mathrm{B}} \quad$ concentration of methanol after time $\mathrm{t},(\mathrm{g} / \mathrm{L})$

$\theta_{B} \quad$ ratio of $\mathrm{C}_{\mathrm{B} 0}$ to $\mathrm{C}_{\mathrm{A} 0}$

$\mathrm{k}$ rate Constant

$\mathrm{t}$ time, $\min$

$\mathrm{X}$ conversion, \%

\section{ACKNOWLEDGMENTS}

Authors acknowledge the financial support provided by the Office of Research and Economic Development (ORED), the Bagley College of Engineering (BCoE), and the Department of Civil and Environmental Engineering (CEE) at Mississippi State University. Special thanks to William Holmes of the Swalm School of Chemical Engineering at Mississippi State University for assistance with the samples analysis.

\section{REFERENCES}

1. Gude, V.G., \& Grant, G.E. (2013). Biodiesel from waste cooking oils via direct sonication, Applied Energy, 109, 135-144.

2. Gude, V.G., Grant, G.E., Patil, P.D., \& Deng, S. (2013). Biodiesel production from low cost and renewable feedstock, Central European Journal of Engineering, 1-11.
3. Wang, Y., Ou, S., Liu, P., \& Zhang Z. (2007). Preparation of biodiesel from waste cooking oil via two-step catalyzed process, Energy Conversion and Management, 48, 184-188.

4. van Kasteren, J.M.N., \& Nisworo, A.P. (2007). A process model to estimate the cost of industrial scale biodiesel production from waste cooking oil by supercritical transesterification, Resources Conservation and Recycling, 50, 442-458.

5. Demirbas, A. (2009). Biodiesel from waste cooking oil via base-catalytic and supercritical methanol transesterification, Energy Conversion and Management, 50, 923-927.

6. Patil, P.D., Deng, S., Rhodes, I., \& Lammers, P.J. (2010). Conversion of waste cooking oil to biodiesel using ferric sulfate and supercritical methanol processes, Fuel, 89, 360-364.

7. Patil, P.D., Gude, V.G., Reddy, H.K., Muppaneni, T., \& Deng, S. (2012) Biodiesel production from waste cooking oil using sulfuric acid and microwave irradiation processes, Journal of Environmental Protection, 3, 107-113.

8. Gude, V. G., Patil, P., Martinez-Guerra, E., Deng, S., \& Nirmalakhandan, N. (2013). Microwave energy potential for biodiesel production, Sustainable Chemical Processes, $1,1-31$.

9. Stavarache, C., Vinatoru, M., Maeda, Y., \& Bandow, H. (2007) Ultrasonically driven continuous process for vegetable oil transesterification, Ultrason. Sonochem., 14, 413417.

10. Stavarache, C., Vinatoru, M., \& Maeda, Y. (2007). Aspects of ultrasonically assisted transesterification of various vegetable oils with methanol, Ultrason. Sonochem., 14, 380386.

11. Ji, J., Wang, J., Li, Y., Yu, Y., \& Xu, Z. (2006). Preparation of biodiesel with the help of ultrasonic and hydrodynamic cavitation, Ultrason. Sonochem., 44, 411-414.

12. Wu, H., \& Zong, M-H. (2007). Effect of ultrasonic irradiation on enzymatic transesterification of waste oil to biodiesel, ACS Symp. Ser., 959, 43-49.

13. Singh, A.K., Fernando, S.D., \& Hernandez, R. (2007). Base catalyzed fast transesterification of soybean oil using ultrasonication, Energy Fuels, 21, 1161-1164.

14. Georgogianni, K.G., Kontominas, M.G., Alvonitis, D., \& Gergis, V. (2006). Transesterification of sunflower seed oil for the production of biodiesel: Effect of catalyst concentration and ultrasonication, WSEAS Trans. Environ. Dev., 2, 136-140.

15. Colucci, J.A., Ernesto, B.E., \& Fabio, A. (2005). Biodiesel from an alkaline transesterifi-cation reaction of soybean oil using ultrasonic mixing, Journal of American Oil Chemical Society, 82, 525-530.

16. Kelkar, M.A., Gogate, P.R., \& Pandit, A.B. (2008). Intensification of esterification of acids for synthesis of biodiesel using acoustic and hydrodynamic cavitation, Ultrason. Sonochem., 15, 188-194.

17. Benitez, F.A. (2004). Effects of the use of ultrasonic waves on biodiesel production in alkaline transesterification of bleached tallow and vegetable oils: Cavitation model, Ph.D. Dissertation, Univ. of Puerto Rico, Mayaguez, 2004.

18. Deshmane, V.G., Gogate, P.R., \& Pandit, A.B. (2009). Ultrasound assisted synthesis of isopropyl esters from palm fatty acid distillate, Ultrason. Sonochem., 16, 345350.

19. Darnoko, D., \& Cheryan, M. (2000). Kinetics of palm oil transesterification in a batch reactor, JAOCS, 77, 12631267.

20. Kusdiana, D., \& Saka, S. (2001). Kinetics of transesterication in rapeseed oil to biodiesel fuel as treated in supercritical methanol, Fuel, 80, 693-698. 
21. Noureddini, H., \& Zhu, D. (1997). Kinetics of transesterification of soybean oil, Journal of American Oil Chemists Society, 74, 1457-1463.

22. Al-Zuhair, S. (2005). Production of biodiesel by lipasecatalyzed transesterification of vegetable oils: A kinetics study, Biotechnology Progress, 21, 1442-1448.

23. He, H., Sun, S., Wang, T., \& Zhu, S. (2007). Transesterification kinetics of soybean oil for production of biodiesel in supercritical methanol, Journal of American Oil Chemical Society, 84, 399-404.

24. Stamenkovic, O.S., Todorovic, Z.B., Lazic, M.L., Veljkovic, V.B., \& Skala, D.U. (2008). Kinetics of sunflower oil methanolysis at low temperatures. Bioresource Technology, 99, 1131-1140.

25. Georgogianni, K.G., Kontominas, M.G., Pomonis, P.J., Avlonitis, D., \& Gergis, V. (2008). Conventional and in situ transesterification of sunflower seed oil for the production of biodiesel, Fuel Processing Technology, 89, 503-509.

26. Jain, S., \& Sharma, M.P. (2010). Kinetics of acid base catalyzed transesterification of Jatropha curcas oil, Bioresource Technology, 101, 7701-7706.

27. Zheng, S., Kates, M., Dube, M.A., \& McLean, D.D. (2006). Acid-catalyzed production of biodiesel from waste frying oil, Biomass and Bioenergy, 30, 267-272.

28. Dasari, M.A., Goff, M.J., \& Suppes, G.J. (2003). Noncatalytic alcoholysis kinetics of soybean oil, JAOCS, 80, 189192.

29. Diasakou, M., Louloudi, A., \& Papayannakos, N. (1998). Kinetics of the non-catalytic transesterification of soybean oil, Fuel, 77, 1297-1302.

30. Tesser, R., Di Serio, M., Guida, M., Nastasi, M., \& Santacesaria, E. (2005). Kinetics of oleic acid esterification with methanol in the presence of triglycerides, Industrial and Engineering Chemistry Research, 44, 7978-7982..

31. Karmee, S.K., Mahesh, P., Ravi, R., \& Chadha, A. (2004). Kinetic study of the base-catalyzed transesterification of monoglycerides from pongamia oil, Journal of the American Oil Chemists Society (JAOCS), 81, 425-430.

32. Leevijit, T., Wisutmethangoon, W., Prateepchaikul, G., Tongurai, C., \& Allen, M. (2004). A second order kinetics of palm oil transesterification. The Joint International Conference on Sustainable Energy and Environment (SEE), Hua Hin, Thailand. 3-025 (O).

33. Aranda, D.A.G., Santos, R.T.P., Tapanes, N.C.O., Ramos, A.L.D., \& Antunes, Octavio, A.C. (2008). Acid-catalyzed homogeneous esterification reaction for biodiesel production from palm fatty acids, Catal Lett., 122, 20-25.

34. Parkar, P.A., Choudhary, H.A., \& Moholkar, V. S. (2012). Mechanistic and kinetic investigations in ultrasound assisted acid catalyzed biodiesel synthesis, Chemical Engineering Journal, 187, 248-260.

35. Mahamuni, M.N., \& Adewuyi, Y.G. (2009). Optimization of the synthesis of biodiesel via ultrasound-enhanced base-catalyzed transesterification of soybean oil using a multi-frequency ultrasonic reactor, Energy Fuels, 23, 2757-2766.

36. Deshmane, V.G., Gogate, P.R., \& Pandit, A.B. (2009). Ultrasound assisted synthesis of isopropyl esters from palm fatty acid distillate, Ultrasonics Sonochemistry, 16, 345-350.

37. Deshmane, V.G., \& Adewuyi, Y.G. (2013). Synthesis and kinetics of biodiesel formation via calcium methoxide base catalyzed transesterification reaction in the absence and presence of ultrasound, Fuel, 107, 474-482.
38. Avramovic, J.M., Stamenkovic, O.S., Todorovic, Z.B., Lazic, M.L., \& Veljkovic, V.B (2012). Empirical modeling of ultrasound assisted base-catalyzed sunflower oil methanolysis kinetics, Chemical Industry and Chemical Engineering Quarterly, 18, 115-127.

39. Vyas, A.P., Verma, J.L., \& Subrahmanyam, N. (2011). Effects of molar ratio, alkali catalyst concentration and temperature on transesterification of jatropha oil with methanol under ultrasonic irradiation, Advances in Chemical Engineering and Science, 1, 45-50.

40. Lee, K-W., Yu, J.X., Mei, J.H., Yan, L., Kim, Y-W., \& Chung, K-W. (2007). A kinetic study on the transesterification of glycerol monooleate and soyben used frying oil to biodiesel, J. Ind. Eng. Chem., 13, 799-807.

41. Karabas, H. (2013). The optimum production parameters of methyl ester from acorn kernel oil, Environmental Progress and Sustainable Energy, 1-4.

42. Dastjerdi, Z., \& Dube, M.A. (2013). Acid-catalyzed esterification of naphthenic acids, Environmental Progress and Sustainable Energy, 32, 406-410.

43. Shonnard, D.R., Williams, L., \& Kalnes, T.N. (2010). Camelina-derived jet fuel and diesel: sustainable advanced biofuels, Environmental Progress and Sustainable Energy, 29, 382-392.

44. Zaimes, G.G., \& Khanna, V. (2013). Environmental sustainability of emerging algal biofuels: A comparative life cycle evaluation of algal biodiesel and renewable diesel, Environmental Progress and Sustainable Energy, 1-11.

45. Suslick, K.S. (1990). The chemical effects of ultrasound, Science, 24, 1439.

46. Suslick, K.S., \& Crum, L.A. (1997). Sonochemistry and Sonoluminescence. In: Crocker MJ, [Ed.] Encyclopedia of Acoustics, (pp. 271-282). New York:John WileyInterscience.

47. Singh, A.K., \& Fernando, S.D. (2007). Reaction kinetics of soybean oil transesterification using heterogeneous metal oxide catalysts, Chem. Eng. Technol., 30, 12, 1716-1720.

48. Helwani, Z., Othman, M.R., Aziz, N., Fernando, W.J.N., \& Kim, J. (2009). Technologies for production of biodiesel focusing on green catalytic techniques: A review, Fuel Processing Technology, 90, 1502-1514.

49. Patil, P.D., Gude, V.G., Pinappu, S., \& Deng, S. (2011). Transesterification kinetics of Camelina sativa oil on metal oxide catalysts under conventional and microwave heating conditions. Chemical Engineering Journal, 168, 1296-1300.

50. Krishnan, D., Dass, D.M. (2012). A kinetic study of biodiesel in waste cooking oil. African Journal of Biotechnology, 11, 9797-9804.

51. Van Manh, D., Chen, Y.-H., Chang, C.-C., Chang, M.-C., \& Chang, C.-Y. (2011). Biodiesel production from Tung oil and blended oil via ultrasonic transesterification process, Journal of the Taiwan Institute of Chemical Engineers, 42, 640-644.

52. Alternative Fuels Data Center - Fuel Properties Comparison. http://www.afdc.energy.gov/ accessed on 08/04/2013.

53. Cintas, P., Mantegna, S., Gaudino, E.C., \& Cravotto, G. (2010). A new pilot flow reactor for high-intensity ultrasound irradiation. Application to the synthesis of biodiesel, Ultrason Sonochem, 17, 985-989.

54. Gole, V.L., \& Gogate, P.R. (2012). A review on intensification of synthesis of biodiesel from sustainable feed stock using sonochemical reactors, Chemical Engineering and Processing, 53, 1-9. 